\title{
The Survey on Migration of Rural Populations to Urban in Iranian Villagers: A Case Study in Naein Region in the Center of Iran
}

\author{
Ali Salavati
}

\begin{abstract}
The present study, has been done about Naein borough rurals. Naein is located in the center of Iran. The aim of the research was finding the factors affecting migration of Naein rural such as Eshratabad, Balan and Mazyak to the cities, such as Isfahan and Ardestan. The results showed that economic and social reasons such as little raining which leads to decrease of income, decrease of agricultural productions, personality handicraft and stockbreeding, total income; the exploitation of final water resources; lack of new life welfare resources; geographic isolation; and undesirable transport systems are the major reasons for the migration of Naein rural. Also rural entered to capital cities because of football sport, as well as working in railway and industrial manufacturing. Of course positive state projects such as Village Hadi project and Shaid Rajaei project caused returning of some groups of immigrants to villages.
\end{abstract}

Index Terms - Economic and social reasons, Iran, migration, rural.

\section{INTRODUCTION}

The migration is geographic movement or translocation, performed between two geographic areas [1]. The Isfahan state capital building information and statistical register reported an analysis of migration of rural to Naein as shown in Table I.

TABLE I: THE INFORMATION OF MIGRATION OF RURAL TO NAEIN IN 2006

\begin{tabular}{ccc} 
& Ne]. & \\
\hline \hline Net migration & $\begin{array}{l}\text { Number of } \\
\text { emigration }\end{array}$ & Number of immigration \\
\hline 735 & 7880 & 7045
\end{tabular}

The widespread migration from rural to urban territories cause problems including high urban unemployment and poverty [3].

Also, the information about population of Naein city and the villages around it is shown in Table II.

TABLE II: THE POPULATION HOUSEHOLD NUMBERS OF RURAL AND URBAN POINTS IN NAEIN IN 2006 [2].

\begin{tabular}{cccccc}
\hline \hline \multicolumn{2}{c}{ Setter in rural points } & \multicolumn{2}{c}{ Setter in urban points } & \multicolumn{2}{c}{ total } \\
\hline Population & Household & Population & Household & Population & Household \\
& 5598 & 37146 & 10351 & 55755 & 15949 \\
\hline 18609 & & & & & \\
\hline
\end{tabular}

Manuscript received in November 9, 2012; revised January 1, 2013. This work was supported in part by Department of Social Sciences, Naein Payame Noor University, Isfahan, Iran.

Ali Salavati is with the Department of Social Sciences, Payame Noor University, Iran (e-mail: salavati@na.Isfpnu.ac.ir).

\section{THE STUDY}

\section{A. Basic Subject}

Naein borough in the center of Iran consist of several rural population involving Eshratabad rural, Balan rural, Mazyak rural, Oshan rural and others. The aim of this study was the investigation of major reasons for migration of Naein rurals to the cities such as Naein, Isfahan, Ardestan and Tehran.

\section{B. Research Methodology}

In this research monographic and site search methods was used. The techniques including interview documents studding and library investigations which used for collection of data.

\section{RESULTS}

\section{A. Eshratabad Rural}

This rural with 88 members in thirty six household has seventy percent aged members. Most of people migrated for finding better jobs or income toward capital cites such as Isfahan, Tehran or Naein. Lack of medical services was another reason for migration. However the most reason for migration to foreign countries was creation of profession and high level education for children.

\section{B. Balan Rural}

This rural migrate 6 months of year for service activities to Tehran and Isfahan; and return to the village for agricultural activity the remaining 6 months of the year.

\section{Mazyak Rural}

This village had a population of 210 persons and 30 families. Individuals migrated because of inadequacy of agriculture income and environmental deficiencies. Much of rural migrated on the year of 2010 to the capital cities and involved in the fields of football sport, and working in railway as well as ceramic industrial manufacturing.

\section{Kejan Rural}

A statistical analysis about the population of Kejan rural has been done. The results showed that the population was 1069 in 1976, which was decreased to 573 in 2006, because of migration. The population showed a few increase to 618 in 2010 (Table III).

The important causes of the migration were decrease of income, the exploitation of final water resources, lack of new life welfare resources, geographic isolation and undesirable transport systems. 
TABLE III: THE TRANSFORMATION PROCESS IN POPULATION OF KEJAN RURAL.

\begin{tabular}{rc}
\hline \hline Year & Population \\
\hline 1976 & 7880 \\
\hline 1986 & 1054 \\
\hline 1996 & 755 \\
\hline 2006 & 573 \\
\hline 2010 & 618
\end{tabular}

The important causes of the migration were decrease of income, the exploitation of final water resources, lack of new life welfare resources, geographic isolation and undesirable transport systems.

It is mentioned that a little part of the population decrease is from using family planning politics, which was because of family economic difficulties.

\section{Discussion}

Benson and O'Reilly mentioned that the migrants are not the only people with expectations. In some cases, particularly in Spain but increasingly in other destinations including Panama, Egypt, Costa Rica and Malaysia, local agencies are specifically promoting their destination for 'residential tourism', the extension of tourism through foreign investment in the second-home market. Despite the abundance of literature 10 Lifestyle Migration critiquing the early developments in Spa in, very little attention is paid to the negative. Consequences which can be similar to the environmental, social and cultural degradation wrought by tourism. Nudrali and O'Reilly's chapter uniquely focuses not only on what lifestyle migration means for the working class Britons moving to Didim, but also investigated the ambivalent reception of the extant Turkish population. The Turkish are positive about the financial stimulus brought by investment and in-migration but express a number of concerns, which often mirror their wider ambivalence about their position within the European Union. Some expressed unease about the power and influence incomers might eventually obtain, leaving themselves 'second-class citizens' in their own country. Other anxieties related the degradation that could be wrought by the cultural and religious differences between the two populations; they deprecate the culture of their new British neighbors, on the grounds that they have no community or family values and suggest the incomers have little respect for Turkish cultural values [4].

The other study examines which types of individuals are attracted to or repelled from rural and urban areas in France. Migration decisions among urban centers, suburbs, and rural areas are investigated for three age groups. Differences between locations are assumed to be driven by agglomeration economies and externalities resulting from densities. The results from multinomial mixed logics show that large labor markets attract the youngest and in particular educated individuals. Larger family size favors migration from city centers to suburbs, whereas divorce and widowhood increase the probability of moving to an urban center [5].

Ghaffari Moghadam and sobbuhi showed that agricultural input flexibility from rural-urban migration function was estimated by recursive equation system in Iran. This study has been shown that labor, capital and education level had positive effects; and machinery, and agriculture had negative effects on the migration in Iran. Increasing of rural wages leads to decreased migration and mounting urban wage increased migration [3].

Khan in 2011 has been studied some causes of rural-urban migration among the states and union territories of India. The study also showed the socio-economic determinates of rural-urban migration in short, medium and long distance migration-streams, subjected on the basis of migration defining boundaries. In that study, it has been shown that a majority of the rural migrate to the urban areas due to social factors and male migration is more economic motivated than female migration. Also, social factors such as marriage and migration with household are the major reasons for migration to short or medium distances while the work or employment are the main reasons for migration to far distances [6].

Also, our study in Naein rural (located in the center of Iran) showed that there are major reasons for Naein rural migration, which includes:

1) Economic and social reasons such as decrease of income, agricultural productions, personality handicraft and stockbreeding.

2) The exploitation of final water resources; lack of new life welfare resources

3) Geographic isolation

4) Undesirable transport systems.

Also rural entered to capital cities because of football sport, as well as working in railway and industrial manufacturing.

In the case of life style migration it should been said; in some cases, particularly in Spain but increasingly in other destinations including Panama, Egypt, Costa Rica and Malaysia, local agencies are specifically promoting their destination for 'residential tourism', the extension of tourism through foreign investment in the second-home market [4].

\section{CONCLUSION}

By the analysis of the results obtained in the present study, it can be concluded that improvement of the economic conditions by means of industrial agriculture; increasing the level of education in villages; supporting of handicraft production; improvement of water resources; increasing new life welfare resources and establishment of transport systems will be lead to inhibition of migration in Naein rural as a sample of rural population in Iran.

\section{ACKNOWLEDGMENT}

We thank Naein Payamenoor University, because of financial supports; Naein health center, because of the informational supports; also Mahdyeh Balanian, Mehry Khalesi, Atena Sefidghar and Fatemeh Mehrabian for data collection.

\section{REFERENCE}

[1] S. Tammanna, Introduction to Demography, Third ed., Tehran, Payame noor University publication, Persian language, 2007, pp. 178-179. 
[2] Isfahan province statictical calendar, Isfahan State Capital Building Information and Statistical Register, Tehran, Taknegar publication, Persian language, 2006, pp. 88-89.

[3] Z. G. Moghadam and M. Sobbuhi, "Concideration yhe effective factors on migration from village to city in Iran," in proc. 6th National Conference of Agricultural Economics, Iran, pp. 15-16.

[4] M. Benson and K. O. Reilly, Lifestyle Migration: Expectations, Aspirations and Experiences, UK, Ashgate Publishing, 2009, pp. 1-15.

[5] C. D. Dessendre, F. G. Nagot, and V. Piguet, "Life cycle and migration to urban and rural areas: Estimation of a mixed logit model on french data," Journal of Regional Science, vol. 48, no. 4, pp. 789-824, October 2008.

[6] J. H. Khan, T. Hassan, and A. Shamshad, "Socio-economic causes of rural to urban migration in India," Asia-Pacific Journal of Social Sciences, vol. 3, no. 2, pp. 138-158, September 2007.

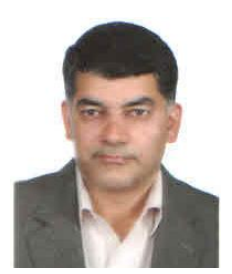

Ali Salavati was born in Isfahan, Iran on March 17, 1968. His educational background includes: Msc in Social sciences, Islamic Azad University, Dehaghan branch, 2000; Bsc in Social sciences, Islamic Azad University, Dehaghan branch,, 1994. The major field of study is rural sociology. He is Lecturer in Social Sciences in Naein Payamenoor University, Naein, Isfahan, Iran and this is the first and current job of him. The previous publications includes: The Study of Factors Affecting Car Accidents (Isfahan, Iran: Payam alavi publication, 2007), The Suvey of the Effect of Islam Religion Expressions in Effectiveness and Labor (Jahrom, Iran, The Added Try and Added Laor Conference, 2011) and The Effect Economic Jihad and Subsidies Targeing Personal in Childish External Medias Smuggled Goods on Use Balance of Internal Sampling (Qom, Iran, Economy Conference, 2011). Mainly interested in rural aspects of social sciences, including the factors affecting rural migration. He had research projects about Isfahan province rural and also had investigations about the biography of prisoners in Iran. Mr. Ali Salavati is a member of Basij Asatid center, Isfahan, Iran from 2000 and International Economics Development Research Center (IEDRC) from 2013. 